\title{
Aktivitas Insektisida Campuran Ekstrak Air Buah Piper aduncum L. (Piperaceae) dan Batang Cymbopogon ciratrus (Dc.) Stapf (Poaceae) Terhadap Larva Crocidolomia pavonana F. (Lepidoptera: Crambidae) \\ Insecticide Activities of Water Extract of of Piper aduncum L. (Piperaceae) Fruit And Cymbopogon citratus (Dc .) Stapf (Poaceae) Stem Against Larva Crocidolomia pavonana F. (Lepidoptera: Crambidae)
}

\author{
Eka Candra Lina, Adventus Supriadi, Yunisman, Martinius \\ Jurusan Hama dan Penyakit Tumbuhan Fakultas Pertanian Universitas Andalas Padang \\ Email : trijata@yahoo.com
}

\begin{abstract}
Crocidolomia pavonana is an important pest in Brassicaceae. Botanical insecticides is pest control alternative which meet to eco-friendly manajement. This study aims to determine lethal concentration of single and mixture of water extract of Piper aduncum (Piperaceae) fruit and Cymbopogon cirtatus (Poaceae) stem against Crocidolomia pavonana larvae. The study was conducted in laboratory experiment through preliminary test and advance test using a completely randomized design (CRD). Observations were included to larval mortality, antifeedant effect, and duration of larval development. Bioassay was done against second instar larvae of $C$. pavonana using leaves immersion method during 48 hours. The results show that $\mathrm{LC}_{50}$ and $\mathrm{LC}_{95}$ value of mixture extract are $2.83 \%$ and $5.79 \%$ respectively. Based on index combination analysis, $P$. aduncum and $C$. citratus mixture extract were antagonistic at $\mathrm{LC}_{50}$ and additive at $\mathrm{LC}_{95}$. Water extract of $P$. aduncum and $C$. citratus were relatively weak to influence feeding activity of $C$. pavonana larvae (41\%). Mixture extract also extend larval development from second instar to third instar around 0.24 days and third instar to fourth instar around 0.97 days.
\end{abstract}

Kata kunci: botanical insecticide, Crocidolomia pavonana, water extract, antagonistic, aditif

\section{PENDAHULUAN}

Ulat Kubis (Brassicae oleracea var. capitata L.) merupakan salah satu komoditas sayuran yang digemari. Kendala utama dalam budidaya sayuran kubis adalah serangan hama dan penyakit yang dapat menyebabkan gagal panen (Sastrosiswojo et. al, 2005). Hama utama pada budidaya kubis adalah Crocidolomia pavonana dan Plutella xylostella, kedua hama ini dapat menimbulkan kerugian $78,81 \%$ hingga $100 \%$ jika tidak dilakukan pengendalian (Kristanto et al., 2013). Petani mengandalkan insektisida sintetis untuk pengendalian hama kubis.
Insektisida sintetik merupakan salah satu sarana penting yang dapat digunakan untuk mengendalikan hama dalam keadaan darurat ketika populasi hama telah mendekati atau melampaui ambang ekonomi (Djojosumarto, 2008), namun dalam jangka panjang hal ini akan menimbulkan kerugian berlipat bagi petani, karena dapat meningkatkan biaya produksi dalam usaha taninya, muncul resistensi dan resurjensi hama sasaran, dapat membunuh hama bukan sasaran, dapat mencemari lingkungan serta bahaya residu pada hasil panen (Rauf et al., 2005).

Untuk mengurangi dampak negatif penggunaan pestisida sintetis, Pemerintah melalui Undang-Undang Nomor 12 Tahun 
1992 tentang Sistem Budidaya Tanaman dan Peraturan Pemerintah Nomor 6 Tahun 1995 tentang Perlindungan Tanaman yang ramah lingkungan yaitu insektisida nabati. Insektisida nabati bersifat selektif, mudah terdegradasi di alam, tidak cepat menimbulkan resistensi jika digunakan dalam bentuk ekstrak kasar, dapat dipadukan dengan teknik pengendalian hama lainnya, dan penyiapan sederhana dapat mengurangi ketergantungan pada produk insektisida sintetis (Lina, 2014).

Beberapa tumbuhan telah dilaporkan memiliki aktivitas terhadap serangga dan memiliki prospek untuk dikembangkan lebih lanjut, salah satunya famili Piperaceae. Sirih-sirih hutan Piper aduncum merupakan salah satu tanaman potensial yang banyak terdapat di Sumatera Barat. Tanaman ini termasuk famili tumbuhan yang telah dilaporkan bersifat insektisida dan menghambat pertumbuhan serangga. Dari hasil uji profil fitokimia buah $P$. aduncum terdapat metabolit sekunder yaitu alkaloid, flavonoid, fenolik, triterpenoid, steroid, saponin dan kumarin (Arneti et al., 2011), pada laporan penelitian tersebut, hasil pengujian fitokimia yang didapatkan sama dengan laporan Klocke et al. (1989) dan Scott et al. (2005) bahwa famili tumbuhan Piperaceae memiliki kandungan kimia dari golongan alkaloid/amida, propenilfenol, lignan, neolignan, terpen, steroid, dan flavonoid. Senyawa piperamida pada famili Piperaceae bekerja sebagai racun syaraf yang menghambat aliran impuls syaraf pada akson sehingga menyebabkan kelumpuhan terhadap serangga uji (Lina, 2014). Jenis tumbuhan lain yang aktif terhadap serangga adalah tanaman sereh (Cymbopogon citratus). Bahan aktif yang terkandung pada sereh adalah saponin dan flavonoid (Yuswantina et al., 2014), sitronella, thymol dan $\alpha$-terpineol (Hummelbrunner dan Isman, 2001) kandungan ini memberikan efek penghambat makan (antifeedant) terhadap serangga uji. Makal et al. (2011) melaporkan bahwa aplikasi ekstrak kasar batang sereh pada konsentrasi $80 \mathrm{~g} / 1$ yang diberikan terhadap larva $C$. pavonana instar II mampu mematikan larva hingga 95\%.
Dadang dan Prijono (2008) menyatakan bahwa insektisida nabati dapat digunakan dalam bentuk campuran ekstrak dua atau lebih jenis tumbuhan. Beberapa keunggulan insektisida nabati yang berbahan baku campuran ekstrak tumbuhan dibandingkan dengan penggunaan ekstrak tunggal diantaranya mengurangi ketergantungan pada satu jenis tumbuhan sebagai bahan baku. Lebih lanjut, penggunaan insektisida dalam bentuk campuran lebih ekonomis bila campuran bersifat sinergis (Stone et al., 1988), dapat meningkatkan spektrum aktivitas insektisida (Dadang dan Prijono 2008). Oleh karena itu, ekstrak $P$. aduncum diharapkan memiliki potensi sinergis jika dicampur dengan bahan lain termasuk jika dicampur dengan ekstrak Sereh C. citratus (Bernard et al. 1995; Fazolin, et al., 2005; Lina, 2014).

\section{METODE PENELITIAN}

\section{Waktu dan Tempat}

Penelitian ini dilaksanakan di Laboratorium Bioekologi Serangga Fakultas Pertanian Universitas Andalas Padang yang dimulai pada September 2015 sampai Januari 2016.

\section{Metode Penelitian}

$\begin{array}{cll}\text { Rancangan } & \text { percobaan yang } \\ \text { digunakan adalah } & \text { Rancangan } & \text { Acak }\end{array}$ Lengkap (RAL). Percobaan ini diawali dengan uji pendahuluan, dengan menggunakan 2 perlakuan dan 3 ulangan. Data yang diperoleh digunakan untuk penentuan taraf konsentrasi pada uji lanjut. Uji lanjut terdiri dari 4 perlakuan dan 5 ulangan pada uji ekstrak tunggal dan 5 perlakuan dan 5 ulangan pada uji ekstrak campuran. Satuan percobaan terdiri dari cawan petri yang berisi 10 ekor larva $C$. pavonana instar II. Dari data yang didapatkan untuk uji ekstrak tunggal konsentrasi ekstrak $P$. aduncum yang digunakan adalah $1,13 \%$ sebagai konsentrasi paling rendah, $1,61 \%, 2,28 \%$ dan $3,25 \%$ sebagai konsentrasi paling tinggi, serta $0 \%$ sebagai kontrol. Kemudian untuk konsentrasi pada ekstrak tunggal $C$. citratus yaitu 3,10\% sebagai konsentrasi 
paling rendah, kemudian $3,87 \%, 4,82 \%$ dan $6 \%$ sebagai konsentrasi paling tinggi serta $0 \%$ sebagai kontrol. Sementara untuk uji lanjut pada ekstrak campuran konsentrasinya $1,50 \%$ sebagai konsentrasi paling rendah, kemudian secara berurut $1,80 \%, 2,20 \%, 2,64 \%$ dan $3,25 \%$ sebagai konsentrasi paling tinggi serta $0 \%$ sebagai kontrol.

Data yang diperoleh dari hasil pengamatan dianalisis dengan analisis sidik ragam dan jika berbeda nyata dilanjutkan dengan uji LSD (Least Significant Different) pada taraf nyata 5\%. Untuk mengetahui nilai kematian pada taraf $\mathrm{LC}_{50}$ dan $\mathrm{LC}_{95}$ digunakan program Polo PC.

\section{HASIL DAN PEMBAHASAN}

\section{A. Hasil}

\section{Mortalitas larva}

\section{a. Uji ekstrak tunggal}

Hasil uji pendahuluan, masingmasing bahan mampu mematikan larva $C$. pavonana dengan mortalitas yang berbeda. Pada ekstrak $P$. aduncum perlakuan dengan konsentrasi $2,50 \%$ dan $5 \%$ berturut dapat mematikan $40 \%$ dan $85 \%$. Pada ekstrak $C$. citratus konsentrasi $2,50 \%$ dan $5 \%$ berturut dapat menyebabkan kematian $23,3 \%$ dan $43,3 \%$ (Tabel 1). Hasil uji lanjut pada pengujian ekstrak tunggal dapat dilihat pada Tabel 2.

Mortalitas larva C. pavonana berkisar $16-54 \%$ pada ekstrak $P$. aduncum dan berkisar antara $12-52 \%$ pada ekstrak $C$. citratus. Ekstrak tunggal $P$. aduncum
Tabel 1. Mortalitas larva C. pavonana akibat perlakuan ekstrak tunggal $P$. aduncum dan ekstrak tunggal C. citratus pada uji pendahuluan.

\begin{tabular}{ccc}
\hline \multicolumn{3}{c}{ Mortalitas (\%) } \\
\hline $\begin{array}{c}\text { Konsentrasi } \\
(\%)\end{array}$ & P. aduncum & C. citratus \\
\hline 0,00 & 0 & 3,3 \\
2,50 & 40 & 23,3 \\
5,00 & 85 & 43,3 \\
\hline
\end{tabular}

memberikan hasil mortalitas lebih tinggi dari ekstrak C. citratus.

\section{b. Uji ekstrak campuran}

Hasil analisis sidik ragam dan uji lanjut LSD taraf 5\% terhadap mortalitas larva $C$. pavonana menunjukkan hasil yang berbeda nyata antara perlakuan (Tabel 3). Terjadi peningkatan

Tabel 3. Mortalitas larva C. pavonana akibat perlakuan ekstrak campuran $P$. aduncum dengan $C$. citratus pada beberapa konsentrasi.

\begin{tabular}{cc}
\hline Konsentrasi (\%) & Mortalitas (\%) \\
\hline 3,25 & $70 \mathrm{a}$ \\
2,64 & $40 \mathrm{~b}$ \\
2,20 & $36 \mathrm{bc}$ \\
1,80 & $22 \mathrm{bcd}$ \\
1,50 & $16 \quad \mathrm{~cd}$ \\
Kontrol & $8 \mathrm{~d}$ \\
\hline
\end{tabular}

Angka-angka pada lajur yang sama dan diikuti oleh huruf kecil sama, berbeda nyata menurut uji lanjut DNMRT pada taraf nyata $5 \%$.

Tabel 2. Mortalitas larva C. pavonana akibat perlakuan esktrak tunggal P. aduncum dan ekstrak tunggal C. citratus pada beberapa konsentrasi.

\begin{tabular}{cccc}
\hline \multicolumn{2}{c}{ P. aduncum } & \multicolumn{2}{c}{ C. citratus } \\
\hline Konsentrasi (\%) & Mortalitas (\%) & Konsentrasi (\%) & Mortalitas (\%) \\
\hline 0,00 & 4 & 0,00 & 6 \\
1,13 & 16 & 3,10 & 12 \\
1,61 & 22 & 3,87 & 24 \\
2,28 & 36 & 4,82 & 30 \\
3,25 & 54 & 6,00 & 52 \\
\hline
\end{tabular}


mortalitas dari konsentrasi paling rendah $(1,50 \%)$ sampai konsentrasi paling tinggi $(3,25 \%)$. Ekstrak campuran konsentrasi $3,25 \%$ menunjukkan aktivitas tertinggi karena mampu mematikan larva uji mencapai $70 \%$.

Untuk mengetahui mortalitas

kumulatif larva $C$. pavonana setelah diberi perlakuan dapat dilihat pada Gambar 3. Dari gambar tersebut dapat dilihat bahwa kematian larva mulai terjadi pada hari pertama pengamatan, kemudian terus meningkat pada hari kedua sampai hari keenam. Secara umum peningkatan mortalitas larva terjadi pada semua taraf konsentrasi namun tidak bertambah secara nyat kecuali pada konsentrasi tertinggi $3,25 \%$ dimana terjadi peningkatan kematian yang sangat nyata. Hal ini disebabkan karena efek antifeedant terhadap larva yang mempengaruhi perkembangan hingga masa pra pupa yaitu hari keenam dan ketujuh

Hasil analisis probit dengan menggunakan Polo-PC menunjukkan perbedaan konsentrasi yang diperlukan untuk mematikan larva C. pavonana antara ekstrak tunggal dan ekstrak campuran (Tabel 4). Pada taraf $\mathrm{LC}_{50}$ dan $\mathrm{LC}_{95}$ kebutuhan konsentrasi lebih rendah setelah bahan dicampur jika dibandingkan dengan ekstrak tunggal. Pada ekstrak tunggal
Tabel 4. Perbandingan nilai $\mathrm{LC}_{50}$ dan $\mathrm{LC}_{95}$ pada ekstrak tunggal dan ekstrak campuran.

\begin{tabular}{lccc}
\hline \multirow{2}{*}{$\begin{array}{c}\text { Nilai } \\
\text { LC }^{a}\end{array}$} & \multicolumn{2}{c}{$\begin{array}{c}\text { Ekstrak } \\
\text { Campuran } \\
(\%)\end{array}$} \\
\cline { 2 - 4 } & $\begin{array}{c}\text { P. } \\
\text { aduncum }\end{array}$ & $\begin{array}{c}\text { C. } \\
\text { citratus }\end{array}$ & $\begin{array}{c}\text { P. aduncum } \\
+ \text { C. citratus }\end{array}$ \\
\hline $\mathrm{LC}_{50}$ & 3,19 & 6,20 & 2,83 \\
$\mathrm{LC}_{95}$ & 12,73 & 11,38 & 5,79 \\
\hline${ }^{a}$ Lethal Concentrate & &
\end{tabular}

membutuhkan konsentrasi 3,19\% sampai $6,20 \%$ untuk mencapai $\mathrm{LC}_{50}$, sedangkan pada ekstrak campuran untuk mencapai $\mathrm{LC}_{50}$ membutuhkan konsentrasi yang lebih sedikit yaitu $2,83 \%$ hal yang sama terjadi pada $\mathrm{LC}_{95}$ Pada ekstrak tunggal membutuhkan konsentrasi $11,38 \%$ sampai $12,73 \%$ untuk mencapai $\mathrm{LC}_{95}$, sedangkan pada ekstrak campuran untuk mencapai $\mathrm{LC}_{95}$ membutuhkan konsentrasi yang lebih sedikit yaitu $5,79 \%$.

Hasil perhitungan nilai Indeks Kombinasi (IK) dari data pengamatan mortalitas larva $C$. pavonana didapatkan bahwa ekstrak campuran $\mathrm{LC}_{50}$ bersifat antagonis dan $\mathrm{LC}_{95}$ bersifat aditif.

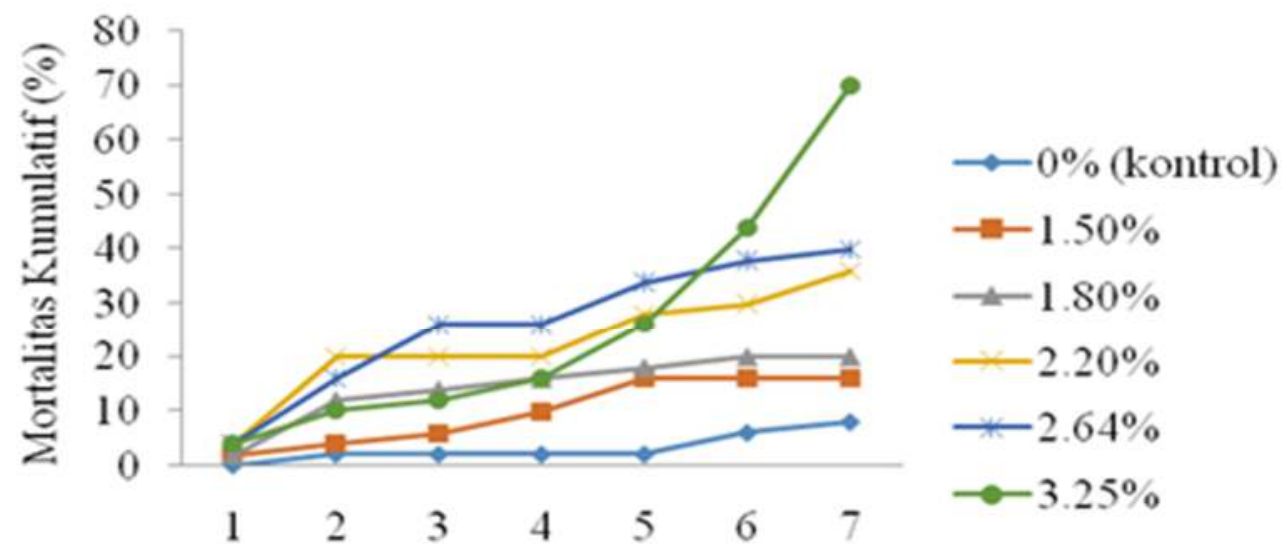

Hari Pengamatan

Gambar 3 Laju mortalitas kumulatif larva $C$. pavonana yang diberi perlakuan ekstrak campuran $P$. aduncum dan C. citratus 
Tabel 5. Nilai indeks kombinasi dua jenis ekstrak buah $P$. aduncum dan batang C. citratus.

\begin{tabular}{ccc}
\hline Taraf & Nilai IK & Kriteria \\
\hline $\mathrm{LC}_{50}$ & 1,72 & Antagonis \\
$\mathrm{LC}_{95}$ & 1,17 & Aditif \\
\hline
\end{tabular}

\section{Aktivitas anti makan}

Hasil pengamatan penurunan aktvitas makan larva uji setelah diberikan perlakuan beberapa konsentrasi ekstrak campuran $P$. aduncum dan $C$. citratus. dapat dilihat pada Tabel 6. Hasil analisis sidik ragam efek antifeedant pada larva $C$. pavonana menunjukkan hasil yang berbeda nyata. Semakin tinggi konsentrasi maka aktivitas larva uji dalam memakan daun perlakuan semakin menurun. Namun demikian jika didasarkan kepada kriteria aktivitas anti makan, campuran ekstrak $P$. aduncum dengan $C$. citratus pada nisbah perbandingan 2:1 masih tergolong lemah

\section{Lama perkembangan larva}

Untuk melihat efek penghambatan pertumbuhan larva $C$. pavonana dalam rentang waktu pengamatan dari instar II sampai instar IV dapat dilihat pada Tabel 7. Selain dapat mematikan larva uji, ekstrak campuran $P$. aduncum dan $C$. citratus juga dapat menghambat perkembangan siklus hidup larva $C$. pavonana. Larva mengalami perlambatan dalam setiap instarnya, mulai dari instar II ke instar II begitu pula dari instar III ke instar IV, meski demikian lama perlambatan jika dibandingkan dengan
Tabel 7. Lama perkembangan larva $C$. pavonana akibat perlakuan campuran ekstrak buah $P$. aduncum dengan batang $C$. citratus

\begin{tabular}{ccc}
\hline \multirow{2}{*}{$\begin{array}{c}\text { Konsentrasi } \\
(\%)\end{array}$} & \multicolumn{2}{c}{$\begin{array}{c}\text { Lama perkembangan (hari) } \\
(\mathrm{X} \pm \mathrm{SD})\end{array}$} \\
\cline { 2 - 3 } & Instar 2-3 & Instar 3-4 \\
\hline 3,25 & $2,37 \pm 0,87$ & $5,00 \pm 1,15$ \\
2,64 & $2,31 \pm 0,52$ & $5,90 \pm 0,96$ \\
2,20 & $2,13 \pm 0,42$ & $5,16 \pm 1,18$ \\
1,80 & $2,31 \pm 0,64$ & $5,40 \pm 1,13$ \\
1,50 & $2,21 \pm 0,60$ & $5,20 \pm 1,09$ \\
0 (kontrol) & $2,13 \pm 0,31$ & $4,93 \pm 1,09$ \\
\hline
\end{tabular}

kontrol yaitu berbeda 0,24 hari dari instar II ke instar III, kemudian pada instar III ke instar IV antara kontrol berbeda 0,97 hari

\section{B. Pembahasan}

Hasil uji pendahuluan P. aduncum dan C. citratus pada konsentrasi $2,50 \%$ dan $5,00 \%$ menyebabkan mortalitas larva uji $C$. pavonana pada perlakuan ekstrak $P$. aduncum lebih tinggi dibandingkan dengan perlakuan ekstrak C. citratus. Kandungan bahan aktif pada masing-masing tanaman mempengaruhi tingkat mortalitas larva $C$. pavonana. Bahan aktif $P$. aduncum yang disebut piperamid bekerja sebagai racun syaraf yang dapat menyebabkan kematian larva uji (Miyakado et al. 1989). Target sasaran adalah ketersediaan sodium seperti pada pyretroid. Toksin menyebabkan saluran sodium pada membran akson tidak.

Tabel 6. Efek antifeedant terhadap penurunan aktivitas larva C. pavonana dalam memakan daun perlakuan.

\begin{tabular}{cccc}
\hline Konsentrasi (\%) & $\begin{array}{c}\text { Luas daun dimakan } \\
\left(\mathrm{mm}^{2}\right)\end{array}$ & Efek antifeedant $(\%)$ & Kriteria \\
\hline Kontrol & 23,02 & $41,0 \mathrm{a}$ & Lemah \\
1,50 & 21,68 & $32,2 \mathrm{ab}$ & Sedikit \\
1,80 & 14,92 & $28,8 \mathrm{abc}$ & Sedikit \\
2,20 & 14,23 & $21,8 \mathrm{bc}$ & Sedikit \\
2,64 & 13,92 & $0,00 \mathrm{bc}$ & Tidak ada \\
3,25 & 12,37 & $0,00 \mathrm{c}$ & Tidak ada \\
\hline
\end{tabular}

Angka-angka pada lajur yang sama dan diikuti oleh huruf kecil yang sama, berbeda tidak nyata menurut uji lanjut DNMRTpada taraf nyata 5\%. 
dapat menutup, akibatnya ion sodium terus menerus melewati membran dan menyebabkan kejang pada serangga (Perry et al. 1998)

C. citratus dengan kandungan saponin dan flavonoidnya bekerja sebagai antifeedant yang menyebabkan larva $C$. pavonana menghentikan aktivitas makan. Selain itu senyawa Sitronella menyebabkan dehidrasi pada larva uji yang juga mengakibatkan kematian (Shahabuddin dan Anshary, 2010). Sifat toksik dan penghambat makan dari bahan aktif ekstrak $P$. aduncum dan $C$. citratus secara bersama-sama akan mematikan larva uji $C$. pavonana.

Pola kematian larva C. pavonana yang diuji dengan ekstrak $P$. aduncum dan C. citratus menyebabkan kematian secara bertahap. Tampak pada Gambar 3 bahwa kematian larva tetap terjadi hingga hari ketujuh pengamatan. Selain itu juga memperlambat pertumbuhan dan perkembangan larva yang bertahan hidup dari instar 2 ke instar 3 dan instar 2 ke instar 4 (Tabel. 7). Hasil uji ekstrak campuran menunjukkan peningkatan mortalitas larva $C$. pavonana dibandingkan pengujian ekstrak tunggalnya. Gejala keracunan mulai tampak pada 3 jam setelah perlakuan. Larva $C$. pavonana terus aktif bergerak menjauhi daun perlakuan. Larva yang diberi daun perlakuan cenderung menempel pada bagian atas cawan petri, sedangkan larva pada kontrol cenderung beraktivitas normal, bersembunyi di bawah daun dan memakan daun seperti biasanya. Setelah 24 jam larva yang diberi daun perlakuan memakan daun dalam jumlah kecil, hal ini disebabkan oleh rasa lapar larva.

Gejala kematian larva C. pavonana instar 2 yang memakan daun terpapar residu bahan aktif $P$. aduncum dan $T$. vogelii diawali dengan menurunnya intensitas gerak larva dan juga aktivitas makan. Berdasarkan nilai Indeks Kombinasi (IK) campuran antara ekstrak $P$. aduncum dan $C$. citratus bersifat antagonis pada $\mathrm{LC}_{50}$ dan campuran bersifat aditif pada $\mathrm{LC}_{95}$. Sifat antagonis menunjukkan bahwa aktivitas insektisida ekstrak campuran lebih lemah dibandingkan dengan ekstrak tunggal
(Veterinary, 2003). Lemah dalam hal ini tidak saja terkait dengan daya bunuh tetapi juga daya penghambat makan dan daya penghambat pertumbuhan dan perkembangan. Sifat aditif menunjukkan bahwa tingkat mortalitas larva uji akibat perlakuan ekstrak campuran pengaruhnya tidak signifikan dengan jumlah tingkat mortalitas akibat perlakuan dengan ekstrak tunggal secara terpisah (Kosman dan Cohen, 1996) lebih lanjut Veterinary (2003) menjelaskan bahwa sifat aditif adalah kondisi tidak ada interaksi antara campuran atau toksisitas campurannya cenderung sama dengan toksisitas ekstrak tunggal.

Pencampuran ekstrak tanaman diharapkan memiliki nilai indeks kombinasi yang bersifat sinergis, sehingga memiliki aktivitas insektisida yang lebih baik dibandingkan ekstrak tunggalnya. Kombinasi yang bersifat sinergis sangat dianjurkan agar memenuhi kriteria mencegah resistensi (Georghiou 1983), dapat meningkatkan spektrum aktivitas insektisida (Dadang dan Prijono 2008), mengurangi pengaruh samping terhadap organisme bukan sasaran dan lingkungan (Prijono 2002) sekaligus menghemat bahan baku dan keunggulan lainnya. Campuran yang bersifat sinergis antara lain yang telah diteliti oleh Yuswanti (2002) menyebutkan bahwa campuran ekstrak Aglaia harmsiana dan Dysoxylum acutangulum menunjukkan efek sinergistik terhadap larva Plutella xylostella dengan nisbah sinergistik pada $\mathrm{LC}_{50}$ dan $\mathrm{LC}_{95}$ masing-masing 3.3 dan1.1. Pada penelitian lain, Yunia (2006) melaporkan bahwa campuran ekstrak $P$. retrofractum dan Swietenia mahogani 1:1 pada konsentrasi $0.05 \%-0.8 \%$ serta campuran ekstrak $P$. retrofractum dan $A$. squamosa $3: 7, \quad 1: 1$, dan 7:3 pada konsentrasi $0.05 \%-0.8 \%$ dapat mematikan $100 \%$ larva $C$. pavonana. Penelitian yang dilakukan oleh (Lina et al., 2013; Lina et al., 2015; Lina et al., 2017) melaporkan bahwa campuran ekstrak $P$. aduncum dan T. vogelii pada perbandingan 5:1. Hasil yang diperoleh, menunjukkan sifat sinergistik kuat dan memiliki aktivitas insektisida terhadap hama C. pavonana, Plutella xylostella, dan Etiella zinkenella. 


\section{KESIMPULAN}

Berdasarkan hasil penelitian dapat disimpulkan bahwa ekstrak campuran bersifat antagonis pada $\mathrm{LC}_{50}$ dan bersifat aditif pada $\mathrm{LC}_{95}$. Hasil analisis probit diperoleh $\mathrm{LC}_{50}$ pada konsentrasi 2,83\% dan $\mathrm{LC}_{95}$ pada konsentrasi $5,79 \%$. Dari konsentrasi terendah $1,50 \%$ sampai konsentrasi tertinggi $3,25 \%$ memiliki pengaruh mortalitas yang berbeda, semakin tinggi konsentrasi maka aktivitas larva uji dalam memakan daun perlakuan semakin menurun. Berdasar kriteria aktivitas anti makan, penurunan aktivitas makan larva $\mathrm{C}$. pavonana hanya $41 \%$ dari kontrol dan efek ini tergolong dalam kriteria lemah. Selain dapat mematikan larva uji, ekstrak buah sirih hutan Piper aduncum dan batang sereh Cymbopogon citratus juga memperpanjang masa larva $C$. pavonana 0,24 hari dari stadia larva instar II ke instar III, dan 0,97 hari dari stadia larva instar III ke instar IV

\section{DAFTAR PUSTAKA}

Arneti, Yaherwandi, I Manti, Dachriyanus. 2011. Keefektifan ekstrak sederhana buah Piper aduncum (Piperaceae) terhadap Crocidolomia pavonana $\mathrm{F}$. (Lepidoptera: Crambidae) untuk penggunaan ditingkat petani. Padang. Universitas Andalas. Manggaro 12:17-22.

Bernard CB, HG Krishnamurty, D Chauret, T Durst, BJR Philogene. 1995. Insecticidal defenses of Piperaceae from the Neotropics $J$ Chem Ecol 21:801-814.

Dadang, D Prijono. 2008. Insektisida Nabati: Prinsip, Pemanfaatan, dan Pengembangan. Departemen Proteksi Tanaman, IPB. Bogor

Djojosumarto P. 2008. Pestisida dan Aplikasinya. Agromedia Pustaka. Jakarta

Fazolin M. JLV Estrela, KKL Yamaghuci, FA Pieri, V Junior. 2005. Amazon Piperaceae With Potential Insecticide Use. Medicinal Plants: Phytochemistry and Therapeutics 3:423-439.
Georghiou GP. 1983. Management of resistance in arthropods. In Georghiou GP, Saito T, editor. Pest Resistance to Pesticides. New York (US): Plenum Press. Pp 769-792.

Hummelbranner LA, MB Isman. 2001. Acute, sublethal, antifeedant and synergistic effects of monoterpenoid essential oil compounds on the tobacco cutworm, Spodoptera litura (Lep., Noctuidae). $J$ of Agriculture and Food Chemistry. 49:715-720

Klocke JA, MF Balandrin, MA Barnby, RB Yamasaki. 1989. Limonoids, Phenolics, and Furanocoumarins as Insect Antifeedants, Repellents, and Growth Inhibitory Compounds. $D i$ dalam: Arnason JT, Philogene BJR, Morand P. (eds). Insecticides of Plant Origin. Washington DC: ACS. Hal 136-149.

Kosman E, Y Cohen. 1996. Procedures for calculating and differentiating synergism and antagonism in action of fungicide mixtures. Phytopathology 86:1255-1264.

Kristanto SP, Sutjipto, Soekarto. 2013. Pengendalian Hama Pada Tanaman Kubis Dengan Sistem Tanam Tumpangsari. Berkala Ilmiah Pertanian. 1:7-9. .

Lina EC, Dadang, S Manuwoto, G Syahbirin, D Priono. 2013. Synergistic action of mixed extracts of Brucea javanica (Simaroubaceae), Piper aduncum (Piperaceae), and Tephrosia vogelii (Leguminosae) against cabbage head caterpillar, Crocidolomia pavonana. J Biopest 6(1):77-83

Lina EC. 2014. Pengembangan formulasi insektisida nabati berbahan ekstrak Brucea javanica, Piper aduncum, dan Tephosia vogelii untuk pengendalian hama kubis Crocidolomia pavonana. [Disertasi]. Sekolah Pasca Sarjana. IPB, Bogor. 
Lina EC, Dadang, S Manuwoto, G Syahbirin. 2015. Gangguan fisiologi dan biokimia Crocidolomia pavoana (F.) (Lepidoptera: Crambidae) akibat perlakuan ekstrak campuran Tephrosia vogelii dan Piper aduncum. Jurnal Entomologi Indonesia 12(2) : 994-101.

Lina EC, Dadang, S Manuwoto, G Syahbirin. 2017. Safety and effectiveness of mixed plants extracts formulation against cabbage pests under field conditions. J Biopest 10(1): 25-34.

Makal, VG Henny, AST Deflly. 2011. Pemanfaatan ekstrak kasar batang serai untuk Pengendalian larva Crosidolomia binotalis zell. Pada tanaman kubis. Eugenia. 17(1):1620.

Miyakado M, I Nakayama, N Ohno. 1989. Insecticidal unsaturated isobutylamides from natural products to agrochemical leads. In Arnason JT, Philogene BJR, Morand $\mathrm{P}$, editor. Insecticides of Plant Origin. Washington DC (US): ACS. $P p$ 173-187.

Perry AS, I Yamamoto, I Ishaaya, RY Perry. 1998. Insecticides in Agriculture and Environment: Retrospects and Prospects. Berlin (DE): Springer-Verlag.

Prijono D. 2002. Pengujian Keefektifan Campuran Insektisida: Pedoman bagi Pelaksana Pengujian Efikasi untuk Pendaftaran Pestisida. Jurusan Hama dan Penyakit Tumbuhan, Faperta IPB

Rauf A, D Prijono, Dadang, IW Winasa, IW Russell. 2005. Survey of pesticide use by cabbage farmers in West Java, Indonesia [Abstract]. Department of Plant Pests and Diseases IPB. Bogor

Sastrosiswojo S, Uhan T.S, Sutarya R. 2005. Penerapan Teknologi PHT Pada Tanaman Kubis. Balai Penelitian Tanaman Sayuran. Bandung
Scott IM, N Gagnon, L Lesage, BJR Philogene, JT Arnason. 2005. Efficacy of botanical insecticides from Piper species (Piperaceae) extracts for control of European Chafer (Coleoptera: Scarabaeidae). J. Econ.Entomol 98(3):845-855.

Shahabuddin, A Anshary. 2010. Uji Aktivitas Insektisida Ekstrak Daun Serai Terhadap Ulat daun Kubis (Plutella xylostella L.) Di Laboratorium. Agroland 17(3): 178-183.

Stone ND, ME Makela, FW Plapp. 1988. Nonlinear optimization analysis of insecticide mixtures for the control of the tobacco budworm (Lepidoptera: Noctuidae). $J$ Econ Entomol 81:989-994.

Veterinary, D. 2003. Cimbined Action and Interaction of Chemicals in Mixtures "The Toxicological Effects of Exporsure to Mixtures of Industrial and Enviromental Chemicals. Danish Ministry of Agriculture, Food and Fisheries.

Yuswanti L. 2002. Pengaruh campuran ekstrak Aglaia harmsiana Perkins dan Dysoxylum acutangulum Miq. (Meliaceae) terhadap mortalitas dan oviposisi Plutella xylostella (L) (Lepidoptera: Yponomeutidae) [skripsi]. Bogor: Jurusan Hama dan Penyakit Tumbuhan, Faperta IPB.

Yuswantina R, K Retno, Sikni, N Lusiana. 2014. Formulasi krim ekstrak batang sereh Cymbopogon nardus sebagai anti fungi terhadap jamur Candida albicans. Semarang. Jurusan Farmasi STIKES NWU. 